\title{
Departmental Leadership: Navigating Productive Tension While in a Paradoxical Role
}

\author{
Rosemary M. Caron * \\ Department of Health Management and Policy, College of Health and Human Services, University of New Hampshire, \\ Durham, NH, United States
}

The landscape of higher education is dynamic and calls for faculty and academic administrators to not only prepare those entering the workforce with current skills, knowledge, and values but to do so in an environment that is resourceful with the tools, and personnel necessary to educate the citizenry. A critical component in achieving this noble mission is the role of the Department Chair, who spans both the academic and administrative environments. The Department Chair, whether at a public or private institution must serve multiple masters which include, senior academic administrators, departmental faculty, staff, students, parents, alumni, community partners, and donors. The challenges that arise while in this role are many, for example, budgetary,

OPEN ACCESS

Edited by: Andy Townsend, University of Nottingham, United Kingdom

Reviewed by:

Kerry Robinson,

University of North Carolina at

Wilmington, United States Katherine Cumings Mansfield,

University of North Carolina at Greensboro, United States

*Correspondence: Rosemary M. Caron Rosemary.Caron@unh.edu

Specialty section:

This article was submitted to Leadership in Education, a section of the journal Frontiers in Education

Received: 18 June 2019

Accepted: 28 August 2019 Published: 12 September 2019

Citation:

Caron RM (2019) Departmental Leadership: Navigating Productive Tension While in a Paradoxical Role.

Front. Educ. 4:97.

doi: 10.3389/feduc.2019.00097 personnel, and academic program accreditation/certification. Successes also do occur as evidenced by enrollment and graduation rates, and sincere appreciation from those we have taught. The Department Chair role is essential and deserves to possess the authority necessary to make decisions that are in the best interest of students, faculty, and the academic programs offered. The purpose of this perspective is to offer recommendations, grounded in experience, that may assist the Department Chair in navigating productive tension that can arise while working in this role that is often paradoxical at times.

\section{Keywords: department chairperson, educational leadership, faculty team building, paradox, transition}

\section{INTRODUCTION}

The role of the Department Chair may vary in public or private academic institutions, yet the commonality is one of a position that works in two realms: academic and administrative. In order to serve as the department's chief academic and administrative officer, often, the Department Chair is a faculty member elected by one's peers and requires the approval of the Dean of the specific college in which the department is housed. At many academic institutions, the only requirement for election to this leadership position is that the faculty member be tenured. Unlike many nonacademic sectors, prior experience, or preparation to serve as a departmental leader is neither required nor provided by the academic institution in many cases.

With little to no preparation for being responsible for the academic programming, and faculty, staff, and students of an academic department, the question remains as to why such a responsibility would be sought after by an academician? Gmelch and Burns (1993) reported, based on a national survey of Department Chairs, that many assumed the role for extrinsic factors (e.g., requested by an authority figure, such as a Dean; did not feel others who were eligible were qualified; sense of duty), or intrinsic factors (e.g., professional development; build 
a robust academic department; mentor junior faculty). Interestingly, Gmelch and Burns (1993) further reported that those Department Chairs who initially responded to serving in this role for primarily intrinsic reasons were more likely to fulfill more than one term as Department Chair.

A productive tension lies at the core of this leadership role in that the Department Chair must serve as a manager, futurist, mentor, and academician. More specifically, the Department Chair is typically responsible for the academic programming offered by a department, and assuring requisite certification, and accreditation requirements are consistently met. Concomitantly, the Department Chair, based on their years of experience and achievements in the discipline to have earned tenure, is often viewed as one who is knowledgeable about the future direction, opportunities, and challenges of the specific field, or discipline. The Department Chair, as part of the role of manager, is also responsible for helping to mentor junior tenuretrack faculty and to advise about their teaching effectiveness, scholarly productivity, and service contributions so that they are progressing on a trajectory that will result, at many institutions, in a positive tenure outcome. Well-prepared faculties are essential to the success of students. Department Chairs also often serve as immediate supervisors to staff (e.g., clinical faculty, lecturers, program coordinators, administrative assistants) who require different evaluation assessments for job performance compared to tenure-track faculty, as well as different professional development support. Another area that a Department Chair must maintain include those achievements that allowed them to have been selected to serve in this leadership role and that includes continued success and productivity as a teacher and scholar. Jenkins (2016) generally outlines the duties of a Department Chair as follows: advocate for faculty (and I would include staff and students), represent the administration, build consensus among faculty, provide a forum for communication, and offer a vision for the department. Table 1 generally outlines the representative roles and responsibilities of the Department Chair (in the author's department).

Based on my recent service as a Department Chair, I have identified several factors as being essential for one to be successful in this role: (1) a cohesive faculty/staff team that is working toward fulfilling an agreed upon mission and vision for the successful preparation of students and the advancement of the specific discipline; (2) the Department Chair must possess the authority to make decisions that are in the best interest for faculty/staff to be successful; and (3) the Department Chair must be able to make informed decisions that progress academic program development, certification, and accreditation. The purpose of this perspective is to offer recommendations, grounded in experience, that may assist the Department Chair in navigating productive tension that can arise while working in this role that is often paradoxical at times.

\section{ADVANCING CHAIRS AS EDUCATION LEADERS}

The Department Chair, whether at a public or private institution must serve multiple masters which include, senior academic administrators, departmental faculty, staff, students, parents, alumni, community partners, and donors. Yet, when does one receive training to serve in this leadership position? Typically, there is no course in graduate school or post-doctoral preparation that allows for one to attain the requisite skills to lead an academic department and communicate with the multitude of constituents. Most often, the requisite skills are noted, via observation, by the faculty member who is working on teaching, scholarship, and service activities as part of being a departmental citizen. Further, many faculty have opinions about what skills and attributes are necessary for someone to be an effective Department Chair and these expectations may vary, thus making it challenging for a Department Chair to be successful in the role when there is a moving target of beliefs from one's peers of what actions constitute an effective or ineffective Department Chair.

To help tenured faculty at the University of New Hampshire (UNH) prepare for serving in this educational leadership role, an Advancing Chairs as Leaders program was developed and co-sponsored by the University's Office of Engagement and Academic Outreach and UNH Advance: Institutional Transformation. This series has evolved to Advancing Academic Leaders, "a leadership development program designed to support the continuous growth of leaders - department chairs, program directors, coordinators, and other academic leaders" which consists of four workshops aimed at leading within frameworks, leading strategically, dimensions of leadership within the academy, and creating and sustaining an inclusive environment (Advancing Academic Leaders, 2019). The series implements guest speakers, small group work, role play, and the sharing of experiences with current and former program, and department leaders.

This program, which schedules the series of workshops over the course of an academic year, provides essential resources, and contact information for offices a faculty member may not have had cause to reach out to prior to serving in this leadership role (e.g., Title XIII, Title IX, and FERPA). This training informs the newly elected Department Chair that there is a community of practice and support on which to call as novel administrative issues arise.

\section{PARADOX IN PRACTICE}

Although training sessions on inclusivity, diversity, and management are informative, I contend that a standardized approach is not applicable when serving in a leadership role that can be as unique as the faculty and the departments that comprise the university. Gmelch and Miskin (1993) discuss the transitions one faces when moving from a faculty member to a Department Chair. Gmelch and Seedorf (1989) call this the "metamorphosis of the department chair." Examples of this metamorphosis include moving from autonomy to accountability where one becomes accountable to senior administration and the faculty and staff for how one spends their time in and away from the office; becoming more political; providing material and monetary resources and the perception that you, as Department Chair, have control over these departmental resources (Gmelch and Miskin, 1993). 
TABLE 1 | Representative duties and responsibilities of the Department Chair.

1. Work with Departmental colleagues to assure the academic quality and integrity of all Department curricula.

2. Convene a minimum of three regular meetings of Department faculty per semester. The meetings shall be conducted according to Robert's Rules of Order.

3. Appoint membership and Chair of committees.

4. With input and assistance from all faculty, coordinate with faculty for the completion of the baccalaureate program review/certification self-study and other such documents.

5. Work with the Director of Graduate Programs and other Program faculty in preparing for periodic accreditation reviews by outside agencies and for periodic reviews by the University of graduate programs.

6. Provide faculty an (annual) evaluation related to quality of baccalaureate and graduate teaching, scholarship and service. For pre-tenure faculty, input will be solicited from the tenured, departmental faculty. In reviews of faculty of all categories/levels of appointment, the Chair will utilize guidelines and position expectations as specified in the current letter of faculty appointment or relevant memorandum of understanding.

7. In a manner consistent with Department guidelines for such reviews, prepare evaluation letter for third year review of tenure track faculty.

8. In a manner consistent with Department guidelines for such reviews, prepare letter of evaluation for promotion and tenure of tenure track Departmental faculty.

9. In a manner consistent with other relevant guidelines provide feedback on teaching performance to Adjunct faculty within the Department.

10. In a manner consistent with College and Department guidelines for such reviews, prepare a written post-tenure assessment.

11. Complete annual personnel reviews of staff for whom the Department is primarily responsible.

12. Provide input to the Dean's office regarding performance and contributions of all faculty with an appointment within the Department.

13. Based, in part, on Departmental faculty input, make recommendations to the Dean regarding faculty appointment and re-appointment.

14. Review and make recommendations to the Dean regarding sabbatical and leave applications from Department's tenure track faculty.

15. Serve as a member of the College's Executive Committee representing the Department.

16. In conjunction with the Director of Graduate Programs and the College's Business Service Center, prepare and manage the Department's budget.

17. Make workload assignments for Departmental faculty, including selection of adjunct faculty, subject to the approval of the Dean of the College.

18. Develop faculty teaching schedules and workload, subject to relevant University and College guidelines.

19. Act as the Department's principal representative to the Dean of the College.

20. Appoint Departmental representatives to Department, College and University committees.

21. Appoint and convene meetings of the Department's external advisory board. Recommendations for membership on this board are sought from Department faculty.

22. Assign office space in consultation with the Dean.

23. Assign appropriate time to each faculty member for scholarly activity in order to meet College and University expectations.

24. Monitor all outside activities engaged in by faculty and ensure compliance with University and contract regulations.

25. Foster productive, interpersonal relationships among faculty and staff.

26. Continue to maintain teaching and research activities, subject to Departmental/College protocols and guidelines on course buyouts and releases.

27. Work with the others, as appropriate, to maintain relations with Departmental alumni.

28. Consistent with Departmental policies on Team-Based Advising, coordinate advising activities of Class Advisers to ensure consistency, and satisfactory progress of students through the major.

29. Review/make determination with pertinent Class Adviser on student petitions related to variation from academic policy.

30. When appropriate, and based on faculty input, be responsible for developing a mechanism for defining faculty merit awards.

31. Work with Departmental administrative staff to update the undergraduate catalog and website annually. (Department of Health Management and Policy Bylaws, University of New Hampshire, 2016)

In my experience as a Department Chair, I found the role to be one of a paradox in practice where although our departmental letterhead and the plaque on my office door stated I was the Chair of the Department, the perception from the faculty is that I am the leader of the department, and am responsible for all that that designation entails. In practice, I possessed very little informal or formal authority to effect change at a programmatic level. Upon reflection, this outcome was due to two main work environment realities: (1) An historical, persistent schism created by departmental faculty, with respect to departmental academic programming (e.g., where one group of faculty was grounded in a traditional health management curriculum and opposed to the interest of other department faculty in expanding the curriculum to offer coursework and practice in health policy and public health); and (2) the inability to implement exceptions to administrative practice or policy when it is in the best interest of a faculty or staff member (e.g., denial of my request by senior administration, during a period of institutional financial concern, to allow a faculty member a course release from the traditional teaching workload for one semester due to significant health issues.) As the faculty and staff are the core of the department, I experienced that in the absence of working with a team mindset among faculty and not being able to work in a supported, discretionary manner significantly impeded my ability, as a Department Chair, to progress department initiatives at a rate of change I was used to experiencing as an autonomous, tenured faculty member in charge of my own teaching and scholarly objectives.

Although these challenges, specific to the department's culture, led the department to being stagnant with respect to curriculum progression, innovative academic programming, and team building, professionally I found a productive tension arise. I viewed these challenges as just that, embedded challenges that preceded my entry to the department as a tenuretrack faculty member, but they were worthy of addressing as I could see potential for progress in the long-term. It is for this intrinsic reason that $\mathrm{I}$ accepted the nomination to serve as Department Chair and try to advance our departmental curriculum and work toward achieving our programmatic mission.

The following are select examples which outline the productive tension I experienced in this paradoxical role: 
- Implementing a leadership philosophy of giving everyone (i.e., faculty, staff, and students) a voice that I would listen to and hear via bi-weekly faculty meetings; weekly meetings with staff; and an open door policy for faculty, staff, and students to share challenges and ideas, and brainstorm feasible solutions. This practice resulted in students communicating concerns and providing evidence about a department faculty person who was failing to teach effectively and grade in a timely manner. As a result, I met with the faculty member to develop a remediation plan that involved working on improving teaching effectiveness via attending workshops at the university's Center for Excellence in Teaching and Learning; and I conducted several peer observations of the faculty member's teaching, and provided constructive feedback. I communicated regularly with the concerned students (and parents) and senior administration about my management of the situation. Despite an improvement in overall student course evaluations at the end of this remediation plan, there were many who wanted to see a more serious consequence and they expressed discontent that I chose to provide a constructive approach for this faculty member.

- Communicating evidence-based issues about our academic programs to senior administration to justify my approach to an issue. One issue that I raised for our faculty to discuss and resolve was a proposal I developed to place our Master of Public Health (MPH) Program on a 1-year hiatus due to departmental trend data which demonstrated a significant decline in enrollment since the MPH Program's inception and challenges with subsequent employment of graduates. A contentious discussion resulted in a majority faculty vote that placed the MPH Program in a 1-year hiatus so a feasibility study for this graduate program could be conducted. Senior administration requested that I have the faculty reverse the vote as a billboard campaign for select graduate programs was pending for which the MPH Program was included, and a reinstatement plan for the graduate program would take too long. The MPH Program received a probationary outcome from its latest accreditation review and recently graduated its smallest class to date.

- Fostering an approach where the faculty and staff serve as a cohesive unit as opposed to working in a siloed approach. We made progress, albeit slowly, as evidenced by the development, and adoption of a new undergraduate curriculum produced by the full faculty complement. This was accomplished at our annual departmental retreat where we set aside a full day to review the most recent academic year from the standpoint of our teaching experiences, student achievement, curriculum review and development, and open faculty positions. I elected to use the faculty and staff's time together to address our curriculum and the divide among health management, health policy, and public health and to introduce an area that healthcare is moving toward called population health. I challenged the faculty to modernize the curriculum to assure we are educating a proficient workforce. We met this challenge by the end of the retreat via a safe space I created that allowed for alternative opinions and perspectives to be heard and considered and for compromise to be the operating principle as we voted to adopt a newly developed curriculum. However, not every faculty member was pleased with the outcome. My term as Chair ended shortly after this meeting and this new curriculum has yet to be implemented.

- Implementing a practice of daily reflection to gain insight about intended and unintended consequences. Reflection has been helpful as I think about the decisions I and/or the faculty made and whether or not they had the intended outcome and the reasons associated with the result; and questioning what I learned from the process; and how would I manage differently in the future. Gmelch and Buller (2015) discuss the importance of reflection in academic administration work as being important for personal and professional growth. This practice often highlighted a productive tension for me due to my value-based leadership philosophy when I had to communicate with faculty, staff, students, and senior administration about the rationale for an unpopular decision or meet with a faculty or staff member and deliver a negative performance evaluation, for example (Gainor, 2017). It is often easier to make a decision that will result in minimal or no conflict, but these choices often stood in opposition with my values (i.e., excellence, integrity, respect, and honesty).

\section{DISCUSSION}

The landscape of higher education is dynamic and calls for faculty and academic administrators to not only prepare those entering the workforce with current skills, knowledge, and values but to do so in an environment that is resourceful with the tools and personnel necessary to educate the citizenry. A critical component in achieving this noble mission is the role of the Department Chair, who spans both the academic and administrative environments. The challenges that arise while in this role are many, for example, budgetary, personnel, and program accreditation/certification. Successes also do occur as evidenced by enrollment and graduation rates and sincere appreciation from those we have taught. The Department Chair role is essential and deserves to possess the authority necessary to make decisions that are in the best interest of students, faculty, staff, and the academic programs offered.

As I reflect on this leadership role, I was not expecting to experience the paradox in practice and policy that was all-pervading, so I consistently worked to provide rationalebased actions that were in the best interest of the faculty, staff, and students. While in this role, the importance of working with a cohesive faculty and staff team who are committed to the department's mission and vision and who can bring their teaching, research, and service efforts to support the work of the team as opposed to working solo was reaffirmed. There are frustrations in any leadership role but the absence of a unified team will leave the most successful leader ineffective.

The Department Chair position is an active one. The leadership approach for which I most closely align while in this role is Bolman and Deal (1991) Reframing Leadership 
model which contends that leaders must respond to their environment. Constructs from this model that I propose could be valuable to a Department Chair in an academic and administrative environment include: organizations work best when they are governed by rationality; the importance of coordination and control; and organizations can be redesigned to adapt to a situation (Bolman and Deal, 1991). Despite efforts to respond to my environment, the short-sighted view seemed to rule my leadership experience as opposed to the long-sighted view I prefer. For example, not being permitted to grant a course release to a faculty member who was managing a significant health condition because it would mean having to hire an adjunct instructor during an institutional financial crisis. Such actions can cause perceptions of being expendable and under-valued. Another example of voting to place our graduate program on hiatus and subsequently asking the faculty to reverse the vote, per senior administration, demonstrated my lack of authority and possibly contributed to the resultant probation accreditation status. Lastly, taking an approach to constructively help a colleague as opposed to an irreversible action has resulted in productivity. There are numerous additional examples, such as where budgetary requests of senior administration to use available discretionary funds that would benefit students and promote an alumni relationship were rejected led to a decrease in faculty and staff morale; and select, minimal faculty support for a graduate program housed off of the flagship campus, etc., I advocate that Department Chairs have the authority to act in a coordinated and adaptive way that benefits their faculty, staff, and students, and considers the impact of their decisions on the broader university environment.

Many faculty say "Yes" to serving as a Department Chair for reasons they deem to be right or honorable. The department is the critical lynch pin of a college, so without a functional department led by a competent faculty member, the college just won't work. Gmelch (2015) states "The department chair position is the most critical role in the university." Hence, my recommendations for encouraging more faculty to serve in this important role include the development of the following:

- Collegiality at all levels of academia and administration is essential for professional working relationships.

- Building a cohesive faculty and staff team is essential for the progression of academic development and student success.

\section{REFERENCES}

Advancing Academic Leaders (2019). Engagement and Faculty Development, University of New Hampshire. Available online at: https:// www.unh.edu/engagement/advancing-academic-leaders (accessed April 18, 2019).

Bolman, L. G., and Deal, T. E. (1991). Reframing Organizations: Artistry, Choice, and Leadership. San Francisco, CA: Jossey-Bass.

Department of Health Management and Policy Bylaws, University of New Hampshire (2016).

Gainor, K. A. (2017). "Virtuous leadership: using spiritual principles to guide department chair work," in Academic Chairpersons Conference Proceedings.
- Clarify the authority and control the Department Chair possesses to those within the department so paradoxes are reduced.

- Productive tension about an issue that involves both academicians and administrators can be progressive provided exceptions, when warranted, to policy, and practice are permissible.

- The requirement of orientation programs, comparable to Advancing Academic Leaders, should be required of all eligible faculty who are considering taking on such a role. A peer-mentoring model would also allow for a network of Department Chairs of varying experience levels to regularly meet to provide professional development and peer support to each other (Thomas-Evans et al., 2016).

The department chair is an essential role that serves as the liaison between faculty and senior administration and I would propose, holds a significant percentage of the input for the strategic direction of the college or university. A model proposed for use in an academic health center, may have applicability in traditional academic institutions where the values of a prospective Department Chair are a priority and are examined to determine their alignment with the institution's values (Grigsby et al., 2004). Subsequent professional development, leadership training, and mentoring may help to retain individuals in the Department Chair position (Grigsby et al., 2004). The understanding of a Department Chair candidate's professional values and how they support (or not) those of senior administration and the institution is worthy of discussion prior to the commitment of both parties to such a dynamic and unique role.

Although this role was not without its challenges (e.g., issues involving personnel, students, faculty, equity, and scheduling, etc.), I am pleased I served my academic institution in this way and I grew professionally as an administrator. As the higher education landscape evolves, I believe the role of the Department Chair may become more instrumental in the success of the academic institution, so I encourage us to reduce existing paradoxes in the role and to work in the space of productive tension as a team.

\section{AUTHOR CONTRIBUTIONS}

The author confirms being the sole contributor of this work and has approved it for publication.
Available online at: http://newprairiepress.org/accp/2017/Leadership/2 (accessed July 30, 2019).

Gmelch, W. H. (2015). Building strategic chairs. Depart. Chair 26, 3-6. doi: $10.1002 /$ dch. 30028

Gmelch, W. H., and Buller, J. L. (2015). Building Academic Leadership Capacity: A Guide to Best Practices. San Francisco, CA: Jossey-Bass.

Gmelch, W. H., and Burns, J. S. (1993). The cost of academic leadership: department chair stress. Innovat. High. Edu. 17, 259-270. doi: 10.1007/BF00917050

Gmelch, W. H., and Miskin, V. D. (1993). Understanding the Challenges of Department Chairs. Leadership Skills for Department Chairs. Bolton, MA: Anker. 
Gmelch, W. H., and Seedorf, R. G. (1989). Academic leadership under siege: the ambiguity and imbalance of department chairs. J. High. Edu. Manage. 5, 37-44.

Grigsby, R. K., Hefner, D. S., Souba, W. W., and Kirch, D. G. (2004). The future-oriented department chair. Acad. Med. 79, 571-577. doi: 10.1097/00001888-200406000-00014

Jenkins, R. (2016). Your To-Do List as Chair. Chronicle of Higher Education. Available onlie at: https://www.chronicle.com/article/Your-To-Do-List-asChair/237052 (accessed July 30, 2019).

Thomas-Evans, M. A., Rybas, N., and Longley, C. (2016). "Seizing the opportunity: creating a chair development network," in Academic Chairpersons Conference Proceedings. Available online at: http://newprairiepress.org/accp/ 2016/Leadership/15 (accessed July 30, 2019).
Conflict of Interest Statement: The author declares that the research was conducted in the absence of any commercial or financial relationships that could be construed as a potential conflict of interest.

Copyright (c) 2019 Caron. This is an open-access article distributed under the terms of the Creative Commons Attribution License (CC BY). The use, distribution or reproduction in other forums is permitted, provided the original author(s) and the copyright owner(s) are credited and that the original publication in this journal is cited, in accordance with accepted academic practice. No use, distribution or reproduction is permitted which does not comply with these terms. 